\title{
POESÍA CHILENA DE FIN DE SIGLO XX. CONFIGURACIÓN DE LA EMERGENCIA POS-87 ${ }^{1}$
}

\section{CHILEAN POETRY AT THE END OF THE $20^{\mathrm{TH}}$ CENTURY. CONFIGURATION OF THE POST 87S EMERGENCY}

\author{
Julián Gutiérrez \\ Universidad de Santiago de Chile (USACH) - CONICYT \\ julian.gutierrezg@usach.cl
}

\section{Resumen:}

El presente trabajo busca identificar, situar y caracterizar la propuesta poética de un conjunto de autores chilenos que, en el marco de la poesía de fines del siglo XX, constituye una manifestación relevante, aunque parcialmente reconocida. Se trata del segmento generacional denominado 'promoción pos87', que emerge en un contexto ligado a la noción de posmodernidad y cuya propuesta discursiva conforma una alternativa diferenciable al interior del actual proceso literario nacional. Sin pretensión de establecer categorías inamovibles ni estancos teóricos, se trata de configurar un corpus que facilite la demarcación de un objeto y que oriente el inicio de un estudio mayor.

Palabras claves: poesía chilena, promoción pos-87, posmodernidad.

\section{Abstract:}

The present paper seeks to identify, locate, and characterize the poetic proposal of a group of Chilean authors that, in the

\footnotetext{
${ }^{1}$ Este trabajo forma parte de la tesis de doctorado en Estudios Americanos, "Poéticas de fin de siglo en Chile y Perú. Territorios de lo utópico". 
context of poetry at the end of the $20^{\text {th }}$ century, constitutes an important manifestation, though partially recognized. It is a generational segment called 'post 87s promotion' that is born in a context bounded to the notion of postmodernity. Its discursive proposal conforms an alternative distinguishable from the previous one on the current literary process. Without the intention of stablishing immovable categories nor theoretical impasses, the intention is to configure a corpus that facilitates the demarcation of an object and leads the start of a bigger research.

Keywords: Chilean poetry, post 87 s promotion, postmodernity.

\section{Introducción}

Mediante una serie de aproximaciones investigativas y muestras antológicas, la tradición crítico-receptiva nacional ha establecido, acerca de la poesía chilena de fines de siglo XX, un orden proyectado fundamentalmente en dos periodos creativos: la poesía de los ochenta y la de los noventa. La primera, en tanto "alternatividad simbólica respecto del discurso ideológico impuesto por la dictadura" (Galindo, "Las metáforas" 96), ha sido asociada a autores nacidos principalmente en la década del cincuenta y a un periodo de publicación de primeras obras circunscrito al decenio 1977-1987. Dentro de los intentos comprensivos que sostienen esta clasificación, destacan el estudio "Poesía chilena de la última década" de Iván Carrasco y la muestra Antología poética de la generación del ochenta de Andrés Morales.

Respecto de la poesía de los noventa, en cuanto escritura de la denominada 'transición posdictatorial' (Sepúlveda, M. 79), ha sido vinculada fundamentalmente a autores nacidos en la década del setenta y que comienzan a publicar durante los noventa. Dos trabajos son claves en este sentido: Poetas chilenos de los noventa. Estudio y antología de Javier Bello y 
Diecinueve. (Poetas chilenos de los noventa) de Francisca Lange. El estudio de Bello, junto con revisar el surgimiento de una serie de grupos y autores que, desde finales de los ochenta, adquirieron presencia a lo largo del país, al momento de delimitar a los poetas de los noventa -denominados también como Los Náufragos (158) - establece un corte de nacimiento reducido al periodo 1967-1977, dejando en la "excepcionalidad" (149) a autores nacidos en años inmediatamente anteriores. Este criterio coincide con el que, diez años después, usa Francisca Lange para configurar su antología Diecinueve, quien, además de aprobar el periodo de nacimiento determinado por Bello, delimita el tiempo de las primeras publicaciones entre 1990 y 1999, dejando afuera incluso a aquellos que, habiendo nacido dentro de la fecha establecida, publican antes de 1990. A su vez, dos años antes que Lange, Raúl Zurita había anunciado en Cantares. Nuevas voces de la poesía chilena la irrupción en Chile de "un impresionante número de poetas cuya fuerza $\mathrm{y}$ originalidad nos remiten, y prácticamente sin mediaciones, a la fuerza y originalidad de los poetas inaugurales" (9). Se trata de cuarenta y dos poetas que constituyen, según Zurita, el puente de un siglo a otro, todos nacidos a partir de 1970. Con ello, reafirmó la exclusión de aquellos nacidos en los sesenta, pero ahora con el justificativo explícito de que estos autores "no han tenido la fuerza colectiva ni probablemente los canales que los nuevos jóvenes se han creado" (15). En otro intento por explicar este descarte -la exclusión de poetas nacidos entre 1960 y $1967-$ del canon de la poesía de los noventa, Magda Sepúlveda, en una nota de su artículo "El territorio y el testigo en la poesía chilena de la Transición", señala que este sería otro grupo, uno anterior denominado 'generación perdida'. Esto por el "desamparo crítico que vivió la poesía cuando comenzó el boom narrativo de Planeta" y por "una manera de escribir y un interés por ciertos temas" (83), que justificarían dicha separación.

Interpelados por esta situación, a través de la antología Fin de siglo. Nueva poesía de los 80 (Santiago: Ventana 
Abierta, 2009), intentamos dar cuenta de este corpus que, de alguna manera, había quedado perdido en la disgregación y la ausencia. Y, ahora, creemos necesario avanzar en su revisión como segmento generacional relevante.

\section{Promoción pos-87: posmodernidad y discursos}

1. La promoción pos-87 constituye uno de los segmentos generacionales relevantes de la poesía chilena de fines del siglo $\mathrm{XX}$ y, debido a dificultades de categorización dentro de los criterios generacionales clásicos o de dinámicas propias de un campo en disputa, ha sido relegada del canon por la crítica establecida. Se trata de autores con más de veinte años de trayectoria creativa y que, en tanto referentes de una expresión poética anclada en la historia finisecular -desde la dispersión-, animan una tradición literaria entendida como proceso activo de movimientos, actores, obras y circunstancias socioculturales. Es una promoción conformada por poetas que nacen fundamentalmente en los años sesenta, que reciben su formación en el contexto de la dictadura militar y que emergen como poetas a finales de los ochenta. Algunos de ellos son: Luis Andrés Figueroa (San Felipe, 1960), Luis Correa-Díaz (Santiago, 1961), Lorenzo Peirano (Santiago, 1962), Andrés Fisher (Washington D. C., 1963), Sergio Rodríguez Saavedra (Santiago, 1963), Pavel Oyarzún (Punta Arenas, 1963), Mario García (Chaitén, 1964), Víctor Hugo Díaz (Santiago, 1965), Bernardo Chandía Fica (Santiago, 1965-2001), Nadia Prado (Santiago, 1966), Harry Vollmer (Osorno, 1966), Armando Roa Vial (Santiago, 1966), Francisco Véjar (Viña del Mar, 1967), Jesús Sepúlveda (Santiago, 1967), Malú Urriola (Santiago, 1967), Jaime Huenún (Valdivia, 1967) y Bernardo Colipán (Osorno, 1967). Las obras de estos autores no solo reflejan propuestas consistentes y heterogéneas, sino que además contribuyen con notable madurez a la ampliación del actual panorama poético del país. 
Entre las características generales que permiten identificar esta promoción, destaca su emergencia en una época de profunda crisis sociopolítica, contexto en el cual dichos autores participaron a través de movimientos estudiantiles, de colectivos culturales y de propuestas escriturales que conformaban un campo literario visto aún, en aquel entonces, como germinal. Se trata de escritores que, tras haber llegado tarde a la épica utópica de los sesenta, tienen que asumir la experiencia de ser testigos de un periodo de devastación y tristeza, en un territorio cercado por una política que, en lo cultural, se orientó al exterminio de cualquier proyecto crítico. Una suerte de generación perdida que, según la crítica establecida, anuncia con rudeza una poesía posutópica atravesada por el síntoma del desencanto (Espinosa). De aquí que se pueda decir que estos poetas no solo comparten edades, vivencias y fechas de publicaciones próximas, sino también cierta "pertenencia a una visión de mundo, una sensibilidad, un lenguaje y una formación relativamente similares" (Sepúlveda, J. 18). Situación que posibilita, en definitiva, la conformación de una idea de cuerpo promocional más o menos específico al interior de la tradición poética chilena.

La nominación "pos-87" da cuenta de un criterio ontológico, puesto que, tal como afirma Jesús Sepúlveda, el corpus textual de dichos autores "emerge en la escena pública sólo hacia el año 1987” (18): en ese año (y en el siguiente) se edita un conjunto de libros de virtual difusión en el mercado nacional de lectores de poesía: La comarca de senos caídos de Víctor Hugo Díaz, Fabla graffiti de Guillermo Valenzuela, Lugar de origen de Jesús Sepúlveda, La manoseada de Sergio Parra y, en 1988, Piedras rodantes de Malú Urriola y Fluvial de Francisco Véjar. De hecho, autores como el propio Jesús Sepúlveda, Gonzalo Millán y Raquel Olea usan el año 1987 como uno de los signos identificatorios de esta promoción. 
En el panorama de esta emergencia, es posible identificar también agrupaciones que, a través de un trabajo colectivo, intentan articular una propuesta más o menos común a lo largo del país. El caso tal vez más emblemático lo constituye el grupo autodenominado Los Bárbaros, conformado por poetas que, a partir de sus experiencias de una degradada urbe santiaguina, se reúnen en torno a la poesía para testimoniar la descomposición de la ciudad letrada, vista como foco civilizador o sueño de un orden, según advierte Jaime Lizama ("La ciudad" 14). Entre los principales integrantes de este grupo figuran Jesús Sepúlveda, Víctor Hugo Díaz, Guillermo Valenzuela, Sergio Parra, Francisco Véjar, Malú Urriola e Isabel Larraín. Sus prácticas culturales, aunque sin tanto sentido orgánico ni refundacional, tuvieron carácter colectivo mediante la participación en lecturas conjuntas y talleres de poesía como del grupo Enotra de la Fundación Pablo Neruda y el taller Fines de Siglo dirigido por Carmen Berenguer. Además de la conformación de proyectos editoriales -como Bajo el Volcán, Surada, Venus Negra y Ediciones de la Hecatombe-, la publicación de la revista Piel de Leopardo y de la antología Ciudad poética post (1992) y la organización de encuentros literarios -como el Festival de los Corazones Duros (1988) y el Primer Encuentro de Poetas Jóvenes (1991)-. Las otras manifestaciones colectivas ocurren fuera de Santiago y al alero de diferentes universidades del país. Entre las más relevantes, destaca la formada en la Universidad Austral de Valdivia, desde donde autores como Óscar Galindo, Bernardo Colipán y Jorge Velásquez logran configurar la denominada 'poesía del sur' a partir de diversas actividades culturales. Entre ellas, la edición de la revista Páginadura (1989-1994), el Encuentro Nacional Poesía al Sur (1992) y la publicación de la antología Zonas de emergencia. Poesía-crítica (1994). Otra expresión posible de mencionar es la que ocurre en la Universidad Católica de Valparaíso, donde autores como Andrés Fisher y Luis Andrés Figueroa establecen lazos de amistad e inician el cultivo de la escritura poética, vinculados al movimiento estudiantil, al periódico cultural El Quiltro (1982- 
1986) y a una cercanía con la obra de autores como Ennio Moltedo y Juan Luis Martínez. O en la Universidad de La Serena, donde se encuentran poetas como el chilote Mario García y los santiaguinos Sergio Rodríguez y Sergio Ojeda.

Un papel significativo en el demarcado de la emergencia de estos poetas, lo cumplen las dos antologías ya mencionadas: Ciudad poética post (Santiago, 1992) y Zonas de emergencia (Valdivia, 1994). Estas muestras, junto con entregar un importante entramado de autores y discursos de la promoción, evidencian la voluntad de señalar y situar el proceso emergente a través de una serie de comentarios críticos que incorporan en sus páginas finales. Ciudad poética post, compuesta por la obra de diez autores (Nicolás Díaz Badilla, Víctor Hugo Díaz, Luis Ernesto Cárcamo, Oscar Galindo, Felipe Moya, Sergio Parra, Jesús Sepúlveda, Malú Urriola, Guillermo Valenzuela y Eduardo Vassallo), contiene dos aproximaciones críticas que son señeras en el demarcado de la promoción, a la que sitúan dentro del contexto posmoderno. Zonas de emergencia, por su parte, junto con seleccionar una muestra de nueve poetas (Mario García, Marcelo Paredes, Jaime Huenún, Harry Vollmer, Bernardo Colipán, Víctor González, Ivonne Valenzuela, Yanko González y Jorge Velásquez), presenta tres comentarios críticos que buscan deslindar el proceso poético emergente y a un grupo situado en el sur del país.

Sin embargo, este periodo no solo se sostiene en las acciones culturales desarrolladas por los poetas aquí identificados, sino también en una recepción crítica posible de ser rastreada desde el brote mismo de la manifestación de esta promoción. Es decir, desde que la poesía de este grupo comenzaba a escribirse $\mathrm{y}$, por lo tanto, cuando era aún una propuesta inexistente. En este sentido, valiosos son los trabajos realizados por sus propios autores, como Luis Ernesto Cárcamo, Oscar Galindo, Yanko González, Bernardo Colipán, Jesús Sepúlveda, Sergio Saldes, Jaime Lizama, Bernardo Chandía 
Fica, Sergio Rodríguez y Álvaro Leiva, por nombrar algunos. A partir de una perspectiva más actual, destacan los trabajos de Patricia Espinosa, Macarena Silva y Magda Sepúlveda. Todos ellos, de una u otra manera, concuerdan en reconocer un espacio cultural constituido por sujetos que coinciden en un escenario común y que, aunque sin formar un "cuerpo homogéneo", logran confluir en una producción poética cuyo despliegue discursivo comienza alrededor del año 1987.

Sergio Saldes, en un intento por situar esta promoción, subraya que el proceso formativo de sus integrantes se desarrolló bajo el régimen dictatorial instaurado en Chile a partir de 1973: "[N]uestra educación media y universitaria -los que la tuvieron- fue durante la dictadura, por tanto, todo el sistema con que fuimos formados fue el sistema que la dictadura implantó". Sin embargo, luego aclara que "es una generación que no tuvo exiliados, ni relegados, y esa es una de las razones de por qué desde el punto de vista de la escritura de la obra, el tema del 73 no aparece. El golpe no es una experiencia vital, directa para nosotros" (cit. en Chandía, párr.3). Por su parte, Jaime Lizama, al poner su atención en la manifiesta voluntad de distanciamiento de esta promoción respecto de las precedentes, señala que no se trataba en estricto rigor de una voluntad de ruptura, políticamente estructurada, y del ahondamiento de un corte al estilo de la vanguardia, sino que la fricción era parte de un entusiasmo y frescura nada de mesiánicos, derivados de síntomas que reconoce en "la decadencia perceptible del régimen autoritario y la indiferencia o distancia respecto del golpe militar en relación con los procesos formativos vitales y de producción" ("Poesía activa" 116). En este mismo sentido, aunque antes, Luis Ernesto Cárcamo había hecho coincidente la gestación productiva de este grupo de poetas con los rasgos de una sensibilidad juvenil cuya experiencia vital ya no estaba fundada en la dictadura, sino en el espectáculo de los cruces: experiencia súbita de la modernización tecnológica, omnipresencia de la cultura de masas y sus reciclajes, influencia 
inagotable de lo audiovisual, nomadías de las hablas, como parte del clima de un horizonte posmoderno que sintoniza con lo que él llama "agonía de la realidad" ("A partir de una mirada" 104). Y será, además, esta disipación de lo real lo que dará consistencia a la desafiliación de la promoción pos-87 respecto de "las acuciantes militancias testimonialistas, neovanguardistas o feministas de los años ochenta" (Lizama, "Poesía activa" 118).

Por lo tanto, más allá de las innegables repercusiones del golpe militar en la identidad de la sociedad chilena, así como de los profundos trastornos ocasionados a los escenarios cultural, económico, social y político del país -incluyendo, por cierto, la poesía de fin de siglo-, la situación contextual de esta promoción tiene que ver fundamentalmente con un contexto global denominado posmodernidad.

2. La posmodernidad hace referencia a una nueva estructura de sentimientos que invade a la gente común, una nueva manera de experimentar, interpretar y estar en el mundo que ha socavado los sentimientos modernistas (Larraín 135). Efecto, a su vez, de la recomposición del escenario económico internacional y la globalización, de la disolución de los horizontes de la revolución y el rompimiento de las promesas del potencial integrador de la modernidad, de la pulverización de los grandes proyectos y la pérdida de la convicción en un progreso homogéneo (Hopenhayn 21).

De esta situación, señala Jorge Larraín, emana un discurso que se liga con el problema de la identidad de una manera contradictoria: "Por una parte, acentúa el descubrimiento del 'otro' y de su derecho a hablar por sí mismo; pero por otra, destaca el descentramiento del sujeto y la pérdida de su identidad" (137). Es decir, por un lado, "pone el acento sobre la cultura como un modo específico de vida o un modo de ser de un pueblo y defiende su derecho a expresarse, a manifestar una verdad que difiere de otras. Pero, por otro lado, 
rechaza la idea de una identidad personal integrada y coherente porque descarta la idea de un sujeto autónomo y capaz de construir discursos" (137). Aquí el sujeto no produce ideas ni crea discursos, es más bien interpelado por discursos que lo constituyen como sujeto.

La base de todo este cambio radica en la nueva concepción de la realidad, que ya no puede reducirse a un solo patrón racional, porque para el posmodernismo la realidad se ha desintegrado en una multiplicidad de simulacros y significantes sin sentido, dirección o explicación fundada. Reina el caos y la fragmentación de las imágenes: "[E]l sistema entero fluctúa en la indeterminación, toda la realidad es absorbida por la hiperrealidad del código y la simulación" (Larraín 138). La realidad no es más que un conjunto de fragmentos e imágenes discontinuas y cambiantes que hacen ilusoria la existencia de un punto de vista comprehensivo o superior que pudiera encontrar un sentido global.

Según Javier Campos, la condición posmoderna puede ser identificada en Chile ya en la producción cultural de principios de la década de los ochenta, coincidiendo con el proceso de consolidación del sistema capitalista, implantado por la dictadura militar, y el plan de transnacionalización, implementado en respuesta a la crisis económica de aquel entonces (78). Y es que, en palabras de Martín Hopenhayn, el efecto combinado de transnacionalización y dinámica tecnológica en la industria cultural tiende a consagrar una era de la cultura descentrada:

La heterogeneidad cultural no alude a la diversidad de expresiones locales y nacionales, sino a la participación segmentada en un mercado globalizado de mensajes que todo lo penetra y lo redefine. La proliferación de bienes, servicios y consumo culturales socava las fronteras 
convencionales entre cultura pesada y liviana, alta y baja, ilustrada y popular, nacional y exógena (...). La estética del collage y del pastiche, tan cara a la sensibilidad postmoderna, no es casual: constituye una metáfora de esta condición de continua recomposición de sensibilidades y mensajes culturales. Epítetos como "hibridez", "sincretismo", "tejidos interculturales", "descomposición y recomposición de signos" se hacen cada vez más frecuentes en el análisis de los procesos culturales actuales (111-112).

Es, entonces, en esta dinámica de disipación de fronteras que hay que situarse para entender una serie de propuestas estéticas que nacen como respuesta a las nuevas condiciones culturales e históricas que vive el país en la década de los ochenta. Entre ellas, formas que dan cuenta de una evidente apertura creativa, como la de Juan Luis Martínez, quien, a partir de La nueva novela (1977), busca destruir los supuestos textuales y extratextuales de la escritura poética y horadarse a sí mismo como discurso integral. Su obra expresa un punto extremo de búsqueda entre las nuevas representaciones poéticas, al intentar la despersonalización total del texto. O la de Raúl Zurita, que, con Purgatorio (1979), intenta superar la noción de texto, para incorporar el espacio del cuerpo y la realidad como soportes de la escritura, explorando también las posibilidades traumáticas del dolor para metaforizar las agresiones sufridas por el cuerpo social. La figura del poeta-autor-sujeto del poema adopta la forma edificante de un redentor posmoderno, que, por medio de la revelación del lenguaje, busca redimir al pueblo oprimido al mismo tiempo que la palabra poética adquiere un poder exorcizante frente a la legitimación bastarda de la palabra estatal, frente a su violencia simbólica y epistemológica (Nómez 141).

La obra de Zurita tiene una evidente filiación con otros poetas posteriores, como el propio Gonzalo Muñoz (Exit, 1981), 
Diego Maquieira (La Tirana, 1983), Carlos Cociña (Aguas servidas, 1981), Rodrigo Lira (Proyecto de obras completas, terminado en 1982, pero publicado en 1984), Eugenia Brito (Vía pública, 1984) y Elvira Hernández (La bandera de Chile, escrita en 1981, aunque publicada en 1991). Autores con quienes asimila la búsqueda de nuevos significantes y espacios de la escritura, la elaboración de elementos gráficos, la despersonalización del sujeto, la autorreflexibilidad y la interacción entre arte y vida. Elementos que alguna vez obsesionaran a las vanguardias y que, a juicio de Iván Carrasco (2002) y Oscar Galindo (2004), se expanden hacia la interdisciplinariedad y la mutación del género poético, en un ente híbrido que incorpora un sinnúmero de formas culturales que obligan a replantear los criterios de lectura.

Entre los poetas mucho más cercanos a la promoción pos-87, y quienes propenden una ampliación de la noción de libro como espacio de codificación abierto, una relativización de la idea de poema como unidad, una exploración en un sujeto escindido que pugna por su reaparición y la indagación en el lenguaje y la historia como lugares de control del poder y la ideología, tenemos a Tomas Harris (Zonas de peligro, 1985) y Alexis Figueroa (Vírgenes del sol inn cabaret, 1986). Autores que, además de desarrollar una escritura asociada a la exploración de los espacios marginales de las urbes latinoamericanas, forjan un modo de escritura muy característico de poetas como Jesús Sepúlveda, Guillermo Valenzuela, Sergio Parra, Víctor Hugo Díaz, Malú Urriola y Harry Vollmer. Importante será, también, para esta promoción la obra de Enrique Lihn, Jorge Teillier, Gonzalo Millán, Carmen Berenguer, Eduardo Llanos y Jorge Montealegre, entre muchos otros que sería largo nombrar (Galindo, "Marginalidad" 193).

Como hemos podido ver, el escenario o lugar de enunciación de la promoción pos-87 tiene que ver fundamentalmente con: 1) un territorio urbano y marginal, 2) un 
horizonte temporal reconocido ya como posmoderno: asociado a la supuesta crisis de los grandes relatos históricos, políticos, culturales y morales y 3) la consecuente apertura a la pluralidad lingüística y de los deseos. Así como también a una "abismidad" planteada por el fuerte cariz libremercadista de los nuevos modelos de sociedad que comienzan a instalarse, tornando "resbaladizos los bordes de lo real" (Cárcamo, "A partir de una mirada" 104).

A pesar de esta vivencia innegable de crisis de las utopías y de las certidumbres históricas, producto de las tragedias y derrumbes asociados a la noción de fin de siglo, en tanto época cruzada por la caída de los socialismos reales, el empobrecimiento social, la implantación del neoliberalismo y la progresiva despolitización -además de la experiencia súbita de modernización tecnológica y la omnipresencia de la cultura de masa (realidades aprendidas en Latinoamérica a "golpes" y no tanto en los libros de Lyotard, como bien señala Cárcamo)-, la instalación de la escritura de los poetas de la promoción pos-87 es vista como testimonio de resistencia. Es decir, un intento por comprender las complejidades de una realidad en despliegue, a través de la presencia de un sujeto que resiste, insistiendo en el ejercicio de una subjetividad que trata -todavía- de indagar en un lenguaje de ruptura capaz de contradecir la normatividad imperante.

3. Los discursos de los poetas de la promoción pos-87, según Oscar Galindo ("Marginalidad" 196), establecen dos hechos característicos. Por una parte, acentúan las claves locales $\mathrm{y}$ parciales de las realidades en que se mueven y, por otra, clausuran las posibilidades de un discurso totalizante o globalizador, por lo cual realzan claves de dispersión escritural, inestabilidad y desconfianza en el lenguaje. Según Galindo, las identidades locales (poblacionales, barriales, étnicas) abren paso a una escritura como espacio definitivamente desjerarquizado de la cultura, en el que la incorporación de registros populares -el 
lenguaje tribal, la cultura de la imagen, la música de consumo o chatarra- cobra un lugar mucho más evidente.

Desde una perspectiva más analítica, y tratando de entender la variedad discursiva de esta promoción, la crítica ha identificado a lo menos tres grandes grupos o zonas diferentes. Una primera que, a decir de Yanko González (178), mueve y retoma la poética lírica asociada a la imaginería de la nostalgia, como resistencia al embate posmoderno, y se repliega en una suerte de "dominio perdido" teillieriano, vinculado a la aldea local, el origen, la infancia, la naturaleza o la palabra como morada, en oposición a una cultura que opera desde la lógica del mercado y desde los circuitos de producción ligados a los medios de comunicación y a la industria cultural. A este grupo es posible vincular parte importante de la obra de los denominados Poetas del Sur: Mario García ((Des)pliegues de papel y follaje, 1995; Los palafitos... del paisaje, 2000), Bernardo Colipán (Pulotre, 1999), Pavel Oyarzún (La cacería, 1989; La jauría desquiciada, 1991; La luna no tiene luz propia, 1994; Patagonia: la memoria y el viento, 1999). Y, en alguna medida, propuestas de autores como Luis Andrés Figueroa (Velas en el agua, 1992; Los secretos, 1996), Sergio Rodríguez (Suscrito en la niebla, 1995; Ciudad poniente, 2000) y Francisco Véjar (Fluvial, 1988; Música para un álbum personal, 1992; Continuidad del viaje, 1994).

Una segunda zona que, según Luis Ernesto Cárcamo, tiene que ver con discursos identificados por un imaginario que entronca con un escenario cultural urbano, pues se mueven "en el ajetreo de lenguajes mezclados y torcidos, contaminados por la ciudad y sus flujos, gestados en las zonas de apertura y abismidad" ("A partir de una mirada" 107) de los tiempos que corren y que, en palabas de Oscar Galindo, se acercan a la idea "de un collage cultural que ofrece certezas de hibridez y mixturas de la sociedad actual y la sensación de carencia de lenguajes posibles y verdades definitivas" ("Lenguaje" 111). En 
esta zona se puede ubicar a gran parte de la propuesta de los integrantes de Los Bárbaros: Sergio Parra (La manoseada, 1987), Víctor Hugo Díaz (La comarca de senos caídos, 1987; Doble vida, 1989; Lugares de uso, 2000), Jesús Sepúlveda (Lugar de origen, 1987; Hotel Marconi, 1998), así como también la de Luis Correa-Díaz (Bajo la pequeña música de su pie, 1990) y Harry Vollmer (Barrio adentro, 1997; Chaucha, 1999), entre otros.

Una tercera zona o imaginario discursivo lo constituye "la mirada de la mujer, de género, que subvierte el orden patrístico de nuestros ethos cultural": "[P]oemas que cuestionan la asignación cultural de los roles masculino/femenino, la definición cultural del género, y se introduce, en una mirada casi analítica, en la puesta en escena de dichos roles en la esfera doméstica, desmadejando sus contenidos simbólicos" (González, Y. 178). En esta zona destacan las producciones de Nadia Prado (Simples placeres, 1992; Carnal, 1998), Malú Urriola (Piedras rodantes, 1988; Dame tu sucio amor, 1994; Hija de perra, 1998) e Isabel Gómez (Pubisterio, 1990; Versos de escalera, 1994; Perfil de muros, 1998).

Más allá de las dificultades que plantea este afán organizativo, al proponer la clasificación de obras que transitan -y que atraviesan fronteras- a través de los distintos territorios demarcados, es importante considerar también el sentido crítico que estos discursos manifiestan respecto de la cultura oficial. Pues las zonas descritas no solo constituyen diferentes estrategias discursivas dentro de un entramado particular (el de la promoción misma que se arma), sino que además, en tanto constitutivas de una promoción emergente, señalan una determinada "alternativa" al interior de un proceso mayor: el de la tradición cultural a la que se incorporan, como siempre ocurre, en una dinámica de aceptación y rechazo, de interacción y de tensión, de continuidad y ruptura. 
En este sentido, la carga contestataria y contracultural, en cuanto elemento clave para integrar una propuesta alternativa o una oposición a los modelos y esquemas provenientes de las instituciones de poder, se da de manera bastante clara en la práctica discursiva de la promoción pos-87. Esto no solo a nivel del contenido y la forma de los discursos mismos, como sería interesante explorar, sino que también en el ámbito del accionar cultural de los integrantes y de algunos símbolos que adoptan como propios.

A nivel de la práctica cultural, esta promoción está compuesta por un grupo de poetas que se instala en un manifiesto disenso respecto de aquellas propuestas que, en términos de estrategia editorial, por ejemplo, dejan entrever una aceptación del discurso económico neoliberal. Frente a la gustosa aceptación expresada por algunos autores de su nuevo rol literario-comercial, como es el caso de los integrantes de la denominada nueva narrativa chilena, la mayoría de los integrantes de la promoción pos-87 optan por otras estrategias de enunciación. Además de desechar la cadena comercial, en la cual el lector es un mero consumidor, y de despreciar la cantidad literaria en aras de la calidad, estos autores buscan abrir espacios y crear redes entre distintas manifestaciones que no tienen cabida ni resonancias en el lugar de la cultura oficialista (editoriales como Planeta y Alfaguara o medios como la "Revista de Libros" de El Mercurio). La mayoría publica sus obras en pequeñas editoriales, asociadas a proyectos colectivos y de carácter independiente, y casi siempre con bajo tiraje y limitada capacidad de distribución. En el ámbito de la difusión, rompen con el campo de la crítica manufacturada por los consorcios editoriales y la prensa comercial, revalorizando la crítica literaria como una escritura que, además de tener la capacidad de tejer una serie de relaciones culturales desde el análisis de los textos, representa un actante esencial para merodear los espacios del poder, gracias a su función política de interferir y resistir en los modos y las relaciones que se imponen 
para comprender la cultura y las lecturas que la mayoría de las veces consensúan con las que el mercado asigna para comprender la literatura y las políticas textuales (Silva 101).

Dentro de los símbolos que "testimonian la condición extraña y extrañada" (Cárcamo, "Ciudad" 51) de la poética pos87, o esa distancia del poeta y de lo poético respecto de la escena oficial, están las figuras del leopardo y del bárbaro. Tanto el leopardo -en cuanto imagen de belleza salvaje, extraña al paisaje urbano, o animal "más astuto, más ágil y más atrevido que el león o el tigre" (Piel 1) - como el bárbaro -asociado a la idea de extranjero que invade cierta frontera, transgrede las buenas maneras, o ese otro carente de civilización, fuera de lo común- constituyen símbolos que hacen referencia a una voluntad crítica, a una fuerza indómita que se instala como amenaza proveniente de los márgenes. Un deseo de "inscribir una identidad de por sí extraña" (Cárcamo, "Ciudad" 53) al orden establecido. Acto retórico, como muy bien nos recuerda Cárcamo, "análogo a aquella figuración simbolista del poetacisne realizada por Charles Baudelaire, en medio de la moderna y modernizadora experiencia citadina del París de mitad del siglo diecinueve" ("Ciudad" 53).

\section{A modo de conclusión}

La promoción pos-87, en tanto demarcación abierta a la redefinición, constituye un segmento generacional significativo dentro de la tradición poética chilena. A pesar de su condición de agrupación desplazada, tal vez por tratarse de creadores incómodos para la lógica ordenadora, de una u otra manera se conecta con dimensiones de otros segmentos de autores identificables en la actualidad: aquellos de los ochenta, generación inmediatamente anterior, y con la promoción siguiente, aquellos que surgen a mediados de los noventa. Su diversidad o heterogeneidad de voces la hacen un eslabón clave 
y necesario de reconocer dentro de un proyecto de continuidad estético-político nacional e incluso latinoamericano.

Además de percibir en las obras de estos autores una tematización de las experiencias de "devastación, dictadura, democracia incapaz, corrupción, cuerpos sometidos y castigados, mercantilización de cada ámbito de la vida", como señala Patricia Espinosa, marcas como la mezcla de alta y baja cultura, la presencia del pastiche y del collage en tanto metáforas de la hibridación, la intertextualidad, la fragmentación y otros, es posible que estas obras se articulen a un contexto mayor asociado a la idea de fin de siglo. Noción que, en Latinoamérica, comienza a hacerse evidente a mediados de la década de los ochenta, cuando se instalan las polémicas sobre la posmodernidad y que alcanza su madurez con el tema del fin de las utopías y del fin de la historia, en medio de la instauración de un escenario neoliberal y de creciente globalización (Devés 202).

Sumado a ello, dentro de su diversidad discursiva, de una u otra manera la mayoría de estas escrituras parecen ser expresiones de una marginalidad urbana y cultural que intenta recuperar la voz o el habla silenciada. Los hablantes de estas obras se cuestionan y autoevalúan, parodiando hasta el pastiche, y, así, se diferencian de las voces de la vanguardia histórica: no se trata de voces proféticas, sino más bien de poéticas del desecho que intervienen sobre capas devaluadas de todo sentido y valor. Pero que insisten, desde el descentramiento y la movilidad, en un resistir a través de una suerte de incomodidad frente a las posibilidades del lenguaje y a las condiciones del mundo.

Ante la efervescencia de esta época en Chile, tanto en lo económico como en lo cultural, permeada por un discurso militar y monetario casi inocente, los poetas pos- 87 responden críticamente y con un objetivo claro: exponer "la mirada más bien desplazada y desjerarquizada de un sujeto que hace crítica 
en un espacio cultural peligrosamente vacío, sin interconexiones o redes posibilitadoras de diálogos" (Lizama "Dossier" 27). Centrados en la figura del poeta-extraño como sujeto crítico y ajeno a la ciudad que recorre, el modo de intervenir de estos autores parece ser claramente político, en su sentido de ruptura y disensión, asumiendo una perspectiva callejera que buscaba descentrar la ciudad como espacio de enunciación.

\section{Bibliografía}

Bello, Javier. "Poetas chilenos de los noventa. Estudio y antología". Tesis de licenciatura. Santiago: Universidad de Chile, 1995.Impresa.

Campos, Javier. "Lírica chilena de fin de siglo y (post) modernidad neoliberal en América Latina". Posdata 1-2 (1998): 78-91. Impreso.

Cárcamo, Luis. "A partir de una mirada abierta y abismal". Ciudad poética post. Ed. Luis Cárcamo y Oscar Galindo. Santiago: INJUV, 1992. 101-108.impreso.

---. "Ciudad poética en la transición chilena". Revista de Crítica Cultural 31 (2005): 51-58.impreso.

Carrasco, Iván. "Interdisciplinariedad, interculturalidad y canon en la poesía chilena e hispanoamericana actual". Estudios Filológicos 37 (2002): 199-210. Impreso.

---. "Poesía chilena de la última década (1977-1987)". Revista Chilena de Literatura 33 (abril 1989): 31-46. Impreso.

Chandía, Bernardo y Sergio Rodríguez. "Intimidad urbana, huellas de los últimos poetas del siglo veinte". CyberHumanitatis 14. Otoño 2000. 7 marzo 2016. <http://www.revistas.uchile.cl/index.php/RCH/article/view Article/9096/9076 >

Devés, Eduardo. El pensamiento latinoamericano en el siglo XX (tomo III). Buenos Aires: Biblos, 2004.Impreso.

Espinosa, Patricia. "La poesía chilena en el periodo 1987-2000". Letras.s5. Proyecto patrimonio. 2006. 7 marzo 2016. <http://www.letras.s5.com/pe120706.htm> 
Galindo, Oscar. "Interdisciplinariedad en las poesías chilena e hispanoamericana actuales". Estudios Filológicos 39 (septiembre 2004): 155-165. Impreso.

---. "La poesía del sur: nuevas voces y nuevos problemas". Zonas de emergencia. Poesía-crítica. Ed. Bernando Colipán y Jorge Velásquez. Valdivia: Páginadura, 1994. 149-154. Impreso.

---. "Las metáforas impuras. Escritura, sujeto y realidad en la poesía chilena actual". Tesis doctoral. Madrid: Universidad Complutense, 1999. Impreso.

---. "Lenguaje, margen y ciudad. Notas sobre la escena poética post". Ciudad poética post. Ed. Luis Cárcamo y Oscar Galindo. Santiago: INJUV, 1992. 109-113.Impreso.

---. "Marginalidad, subjetividad y testimonio en la poesía chilena de fines de siglo". Revista de Crítica Literaria Latinoamericana 58 (2003): 193-213. Impreso.

González, Máximo. Claves para entender la literatura emergente de fin de siglo. Santiago: Universidad Tecnológica Metropolitana, 1999.Impreso.

González, Yanko. "Ritos de paso. Joven poesía emergente: sur de Chile y otros horizontes". Zonas de emergencia. Poesíacrítica. Ed. Bernando Colipán y Jorge Velásquez. Valdivia: Páginadura, 1994. 155-179. Impreso.

Hopenhayn, Martín. Ni apocalípticos ni integrados: aventura de la modernidad en América latina. Santiago: Fondo de Cultura Económica, 1994. Impreso.

Lange, Francisca. Diecinueve (Poetas chilenos de los noventa). Santiago: J. C. Sáez, 2006. Impreso.

Larraín, Jorge. ¿América Latina moderna?: globalización e identidad. Santiago: Lom Ediciones, 2005. Impreso.

Lizama, Jaime. "Dossier crítica". Piel de Leopardo 4 (19931994): 27-32. Impreso.

---. "La ciudad de la furia". Piel de Leopardo 1 (1992): 12-15.

---. "Poesía activa: poesía de fin de siglo producción/recepción en antologías". Posdata 1 y 2 (1998): 116-123. Impreso. 
Millán, Gonzalo. "Sobre los lugares de uso". Lugares de uso. Por Víctor Hugo Díaz. Santiago: Cuarto Propio, 2000. Impreso.

Morales, Andrés. Antología poética de la generación del ochenta. Santiago: Mago Editores, 2010. Impreso.

Nómez, Naín. "Transformaciones de la poesía chilena entre 1973 y 1998". Estudios Filológicos 42 (2007):141-154. Impreso.

Olea, Raquel. "Entrañado extrañamiento del post poeta". INTI 55-56 (2002): 187-190. Impreso.

Sepúlveda, Jesús. "La generación post 1987”. Licantropía 8 (1998): 18-23. Impreso.

Sepúlveda, Magda. "El territorio y el testigo en la poesía chilena de la Transición”. Estudio Filológico 45 (2010): 79-92. Impreso.

Silva, Macarena. "Revista Piel de Leopardo: a la caza de la Nueva Narrativa y de los jaguares de la transición". Literatura y Lingüística 23 (2011): 101-120. Impreso.

Zurita, Raúl. Cantares. Nuevas voces de la poesía chilena. Santiago: Lom Ediciones, 2004. Impreso.

S/a. "Editorial". Piel de Leopardo 1 (1992): 1.Impreso. 